Check for updates

Cite this: RSC Adv., 2018, 8, 11574

Received 13th December 2017

Accepted 17th March 2018

DOI: 10.1039/c7ra13289a

rsc.li/rsc-advances

\section{Improving the photovoltaic performance of planar heterojunction perovskite solar cells by mixed solvent vapor treatment $\dagger$}

\author{
Binbin Yuan, ${ }^{\text {ab }}$ Suling Zhao, (D) *ab Zheng Xu, ${ }^{\text {ab }}$ Dandan Song, ${ }^{\text {ab }}$ Bo Qiao, (D) ${ }^{\text {ab }}$ \\ Yang Li, ${ }^{a b}$ Zilun Qin, ${ }^{a b}$ Juan Meng ${ }^{a b}$ and Xurong X $u^{\text {ab }}$
}

\begin{abstract}
The grain size of perovskite films is a key factor to optimize the performance of perovskite photovoltaic devices. Herein, a new route is developed in this paper to prepare $\left.\mathrm{CH}_{3} \mathrm{NH}_{3} \mathrm{Pbl}_{3}(\mathrm{MAPb})_{3}\right)$ films with a better morphology and crystallization. This method includes the spin coating deposition of perovskite films with a precursor solution of $\mathrm{Pbl}_{2}$ and $\mathrm{CH}_{3} \mathrm{NH}_{3} \mathrm{l}$ at the molar ratio $1: 1$ and thermal annealing (TA). The thermal annealing is conducted with a thermal-induced process to realize grain growth with solvent evaporation. In addition, a mixed solvent vapor treatment in acetic acid with chlorobenzene (HAc/CB) improves the morphology and crystallization of films further. As a result, the photovoltaic device based on the perovskite film treated by mixed HAc/CB solvent exhibits the best efficiency of $13.15 \%$ in comparison to the control device with $11.44 \%$ under AM $1.5 \mathrm{G}$ irradiation $\left(100 \mathrm{~mW} \mathrm{~cm}{ }^{-2}\right)$.
\end{abstract}

\section{Introduction}

The hybrid organolead halide perovskite solar cells (PSCs) have attracted much attention due to their controlled composition, lower-cost organic components, high charge carrier mobility properties, ${ }^{\mathbf{1 , 2}}$ extremely low trap-state density, ${ }^{3}$ lesser exciton binding energy, ${ }^{4}$ longer charge carrier diffusion length ${ }^{5,6}$ and excellent absorption coefficient. ${ }^{7}$ At present, the power conversion efficiencies (PCE) of PSCs has increased rapidly to $22.1 \%$ since perovskite solar cells were first reported in 2009. ${ }^{\mathbf{8} 9}$ PSCs have offered a promising route to fabricate solar cells via lowcost manufacturing process compared with traditional thinfilm photovoltaic cells such as CIGS solar cells, ${ }^{\mathbf{1 0}}$ which are the new comers of the third-generation photovoltaic devices. Several typical technique processes to fabricate PSCs have been developed recently, including the solution-processed method, ${ }^{11-13}$ the vacuum vapor phase deposition ${ }^{\mathbf{1 4}}$ and other combination thereof. ${ }^{15}$ Compared with other methods, the solution process has great advantages due to the simple process and the low deposition equipment costs.

Furthermore, the solvent engineering has been proven to be a resultful deposition technology to enhance the grain size and uniform perovskite layers. ${ }^{16-20}$ Sang II Seok et al. declared that dimethyl sulfoxide (DMSO) served as a cosolvent with the

${ }^{a}$ Key Laboratory of Luminescence and Optical Information (Beijing Jiaotong University), Ministry of Education, Beijing 100044, China.E-mail: slzhao@bjtu.edu.cn ${ }^{b}$ Institute of Optoelectronics Technology, Beijing Jiaotong University, Beijing 100044, China

$\dagger$ Electronic supplementary information (ESI) available. See DOI: 10.1039/c7ra13289a gamma-butyrolactone (GBL) solution dissolving $\mathrm{CH}_{3} \mathrm{NH}_{3} \mathrm{I}$ (MAI) and $\mathrm{PbI}_{2}$ via one-step spin coating method, ${ }^{21}$ which boot the dissolubility of perovskite precursor and form dense films. Subsequently, they kept meliorating the techniques by a method with direct intramolecular exchange of DMSO molecules intercalated in $\mathrm{PbI}_{2}$ involving formamidinium iodide (FAI) via a sequential two-step coating method. ${ }^{22}$ Then they further elucidated that DMSO strongly interacts with DMSO and $\mathrm{PbI}_{2}$, and retard crystallization of the perovskite films. As we all known, a few polar organic molecules (e.g. DMSO, DMF) easily were absorbed into the perovskite materials. ${ }^{23,24}$ The residual solvent in perovskite films dramatically destroy the crystal structure, which accelerated the ion migration and lattice deformation on account of charges accumulation and then weaken the stability of the perovskite layers. ${ }^{25}$ A long time and high temperature annealing process would remove the residual molecules at the cost of losing counter ions in the surface, which increases the thin film defect and shortens the perovskite device performance. ${ }^{26}$ Seok et al. applied the toluene dripcasting treatment during the spinning in one-step process. ${ }^{21}$ Instead of toluene, Nam-Gyu Park et al. account that diethyl ether was a more advisable to remove DMSO and DMF solvent. ${ }^{27}$ Nevertheless, either annealing process or diethyl ether treatment could not entirely remove the residual DMSO and FAI(MAI)-DMSO species. ${ }^{28}$ The solar cells would explicitly deteriorate because that the residuary solvent induced the degradation of perovskite layers. ${ }^{29}$ It is an intractable issue to remove the remnant solvent involved in the preparation process of thin films, especially the solvent still remained in the films after thermal annealing. However, it has not been investigated with 
respect to the PSCs performance so far for the effect of solvent treatment after thermal annealing of perovskite films.

Here, we investigated the PSCs performance with the solvent vapour treatment after the thermal annealing (TA). The $\mathrm{CH}_{3}^{-}$ $\mathrm{NH}_{3} \mathrm{PbI}\left(\mathrm{MAPbI}_{3}\right)$ film preparing process involved one step deposition through perovskite precursor solution and acetic acid (HAc) with chlorobenzene (CB) mixed solvent vapor treatment process $(\mathrm{H} / \mathrm{CVT})$, which could effectively increase the crystallinity and improve the morphology quality. The films prepared based on H/CVT process were characterized by the scanning electron microscope (SEM), the X-ray diffraction (XRD) and time-resolved photoluminescence (PL) decay curves, in comparison with the films with prepared only by one-step thermal annealing (TA) processes. Then the photovoltaic devices were prepared and the dependence of their performance were discussed in the various process conditions. The fabricated photovoltaic devices based H/CVT process exhibited the best PCE up to $13.15 \%$ under AM 1.5G radiation $(100 \mathrm{~mW}$ $\mathrm{cm}^{-2}$ ) and in comparison to control devices with a $14.9 \%$ improvement.

\section{Experimental}

\section{Materials}

$\mathrm{PbI}_{2}$ and $\mathrm{CH}_{3} \mathrm{NH}_{3} \mathrm{I}$ were purchased from Xi'an Polymer Light Technology Corp. Acetic acid (HAc, purity $>99.99 \%$ ) and chlorobenzene (CB) were purchased from Sigma-Aldrich. PCBM was purchased from Nano-C. The precursor solution of $\mathrm{CH}_{3} \mathrm{NH}_{3} \mathrm{PbI}_{3}$ was composed of $\mathrm{PbI}_{2}$ and $\mathrm{CH}_{3} \mathrm{NH}_{3} \mathrm{I}$ with a molar ratio of $1: 1$ and was stirred in a mixture of dimethyl sulfoxide (DMSO) and $\gamma$-butyrolactone (GBL) $(3 / 7, \mathrm{v} / \mathrm{v})$ at $60^{\circ} \mathrm{C}$ overnight. Phenyl-C61butyric acid methyl ester (PCBM) was dissolved in $o$-dichlorobenzene with a concentration of $20 \mathrm{mg} \mathrm{ml}^{-1}$.

\section{Solar cells fabrication and characterization}

All the solar cells were fabricated on indium tin oxide (ITO)coated glass substrates. The ITO substrates were consecutively cleaned in ultrasonic baths containing glass lotion, de-ionized water, ethanol. The cleaned ITO substrates were then blowdried by nitrogen gas. All pre-cleaned ITO substrates were treated by UV-ozone cleaner for $10 \mathrm{~min}$ to improve work function and then transferred into a nitrogen-filled glove box. The filtered PEDOT:PSS (Clevios, Al4083) was coated on ITO glass substrates by spin-coating at 4000 round per minute (rpm) for $40 \mathrm{~s}$ and annealed at $120{ }^{\circ} \mathrm{C}$ for $20 \mathrm{~min}$. The perovskite precursor solution was deposited onto ITO/PEDOT:PSS substrates by a consecutive two-step spin-coating process as described in previous reports, ${ }^{21}$ but using chlorobenzene as an anti-solvent. The as-deposited perovskite films were heat treated with TA and H/CVT process respectively. For the TA process, the perovskite precursor coated substrates were dried onto a hot plate at $100{ }^{\circ} \mathrm{C}$ for $5 \mathrm{~min}$. For the H/CVT process the perovskite film heat treated through TA process was continued treating under thermal condition at $70{ }^{\circ} \mathrm{C}$ for $3 \mathrm{~min}$ in glovebox. For the H/CVT process, the perovskite film were put into Petri dishes (with cover but not sealed) with vapor of mixed solvents of HAc and CB with defined volume ratios $(1 / 50,1 / 25$, $3 / 50, \mathrm{v} / \mathrm{v}$ ). The substrates were treated under thermal condition at $70{ }^{\circ} \mathrm{C}$ without touching the mix-solvent. Afterwards, the PCBM layer was then spin-coated onto the $\mathrm{CH}_{3} \mathrm{NH}_{3} \mathrm{PbI}_{3}$ layer at $1500 \mathrm{rpm}$ for $60 \mathrm{~s}$. Finally, the devices were finished by thermal evaporating $\mathrm{Al}(80 \mathrm{~nm})$ under $4 \times 10^{-4} \mathrm{~Pa}$ vacuum condition. The device area is defined to be the overlap of the ITO and Al electrodes to be $4 \mathrm{~mm}^{2}$.

The current density-voltage $(J-V)$ curves of the devices were measured with a source meter (Keithley 2400) and measurement unit under simulated AM 1.5G sun spectrum with $100 \mathrm{~mW}$ $\mathrm{cm}^{-2}$ irradiation generated by an ABET Sun 2000 solar simulator in air. External quantum efficiency (EQE) was measured by Zolix Solar Cell Scan 100. Ultraviolet-visible absorption spectra were tested on a Shimadzu UV-3101PC spectrophotometer in the $400-800 \mathrm{~nm}$ wavelength range at room temperature. All characterizations were done outside the glovebox and without any encapsulation of the perovskite cells, under constant exposure to ambient atmosphere. Steady-state photoluminescence (PL) spectra were recorded by Horiba FluoroLog Spectrophotometer. PL measurements of the perovskite films were covered with a polymethyl methacrylate (PMMA) layer to prevent degradation from ambient atmosphere. Scanning electron microscope (SEM) measurements were performed using a Hitachi, S-4800 SEM equipped with the energy dispersive X-ray spectrum. X-ray diffraction (XRD) spectra was performed on a D/max 2200v X-ray powder diffractometer equipped with $\mathrm{Cu}-\mathrm{K} \alpha$ radiation $(\lambda=1.540 \AA)$, the data were collected at room temperature in the range of $10-50^{\circ}$.

\section{Results and discussion}

Fig. 1 illustrates the preparation procedure of the $\mathrm{CH}_{3} \mathrm{NH}_{3} \mathrm{PbI}_{3}$ $\left(\mathrm{MAPbI}_{3}\right)$ perovskite films in our research. The pristine perovskite films firstly were prepared based on the study of Seo et al., ${ }^{17}$ in which non-polar solvent chlorobenzene (CB) was dripped onto the substrates surface during spinning. Afterwards, the substrates were transferred onto the heated platform, the perovskite films turn into dark brown quickly. For the $\mathrm{H} / \mathrm{CVT}$ process, the perovskite films were subjected to the postheating treatment, then the perovskite films were put into a Petri dish with the vapor of mixed solvents of HAc and CB. 15 $\mu \mathrm{L}$ mixed solvent was dripped into the Petri dish edge, the assamples were covered by a glass Petri dish rapidly (with cover

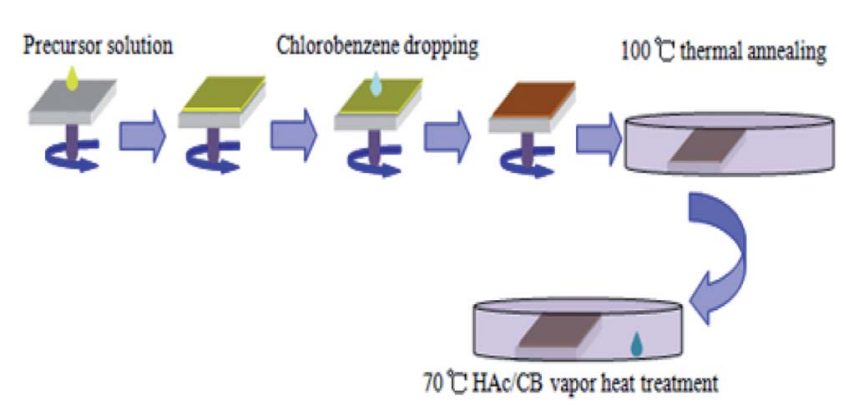

Fig. 1 Schematic diagram of the thermal treatment of perovskite films under solvent vapor. 
but not sealed). The perovskite films were annealed by the mixed solvent of HAc/CB with various volume ratios of HAc (1/ $50,1 / 25,3 / 50, v / v)$. The architecture of the p-i-n PSC with ITO/ PEDOT:PSS/MAPbI $/[$ /6,6]-phenyl-C61-butyric acid methyl ester (PCBM)/Al is schematically shown in Fig. 2(a) and the corresponding energy levels of each layer are shown in Fig. 2(b). The control device with the same structure was also fabricated for the comparation without $\mathrm{HAc} / \mathrm{CB}$ mixing vapor treatment. The $J-V$ characteristic curves of the PSCs of various process conditions are shown in Fig. 3. In addition, the average values of the device parameters obtained from 8 PSCs in each experimental group, which are extracted from the $J-V$ curves are listed in Table 1. According to the photovoltaic performance (Fig. 3 and Table 1), the vapor treatment level for the highest PCE is $1 / 25$ volume ratio of HAc. In order to further investigate the mechanism of the enhanced performance of PSCs with HAc thermal treatment, the superior mixing ratio of $1 / 25$ volume ratio is used in this study. The control group without using HAc/CB mixing vapor treatment has a PCE of $11.44 \%$, which is similar to the values obtained in previous studies for this structure. ${ }^{18,30,31}$ The maximum improvement in PCE is obtained when 1/25 volume ratio mixed $\mathrm{HAc} / \mathrm{CB}$ solvent was used. In this case, the median PCE value increases from $11.44 \%$ to $13.15 \%$, corresponding to a $14.9 \%$ improvement. This improvement in PCE is primarily due to the $7.1 \%$ enhancement of $J_{\mathrm{sc}}$, which increases from 15.38 to $16.47 \mathrm{~mA} \mathrm{~cm}^{-2}$, as shown in Fig. 3 and Table 1. To be fair, our champion control device is $12.05 \%$, which reveals that our control cells show performance comparable to the results reported in Table $2 .{ }^{17,32-36}$

To investigate the main reason responsible for the improvement of $J_{\mathrm{sc}}$, we conduct external quantum efficiency (EQE) measurements to account for the contribution of photocurrent collection to the incoming photon energy. The EQE spectra illustrates a substantial improvement across the visible region when the $\mathrm{H} / \mathrm{CVT}$ process applied as shown in Fig. 4(a). We ascribe the enhancement at the 400 to $800 \mathrm{~nm}$ to the stronger absorption of the $\mathrm{MAPbI}_{3}$ film shown in Fig. 4(b). The $\mathrm{H} / \mathrm{CVT}$ films demonstrate a strong absorption in the range between 400 and $780 \mathrm{~nm}$ with an onset absorption at $800 \mathrm{~nm}$, which corresponds to a bandgap of $1.55 \mathrm{eV}$. The more intense absorption of the films with the acetic acid vapor thermal treatment should also be partially attributed to the more homogenous morphology, which are supported by SEM images of the films discussed later. The EQE measurement of two PSCs follows the same trend of the UV-vis absorption spectra. ${ }^{37}$ The

(a)

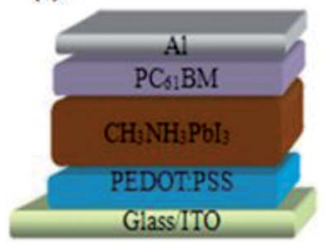

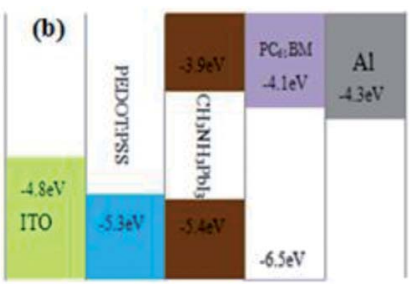

Fig. 2 (a) Schematic device architecture of the $\mathrm{p}-\mathrm{i}-\mathrm{n}$ PSCs constructed by ITO/PEDOT:PSS/ $\mathrm{CH}_{3} \mathrm{NH}_{3} \mathrm{Pbl}_{3} / \mathrm{PCBM} / \mathrm{Al}$; (b) schematic energy band diagram of perovskite solar cells.

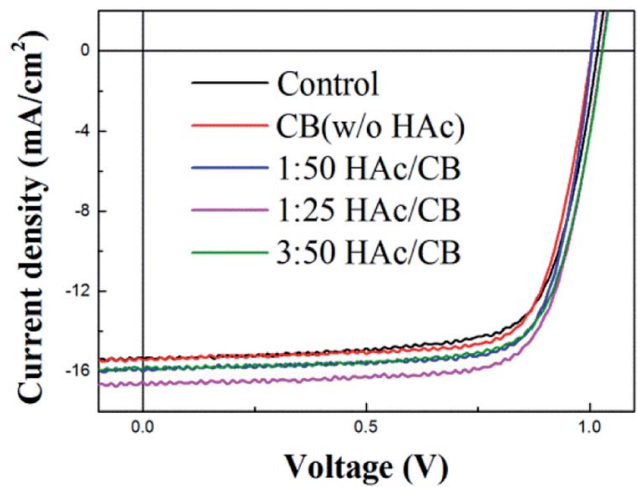

Fig. $3 \mathrm{~J}-\mathrm{V}$ characteristics of $\mathrm{MAPbl}_{3}$ devices with $\mathrm{HAc}$ mixing different volume ratios under $100 \mathrm{~mW} \mathrm{~cm}^{-2}$ (AM 1.5G).

Table 1 Photovoltaic parameters of devices by thermal treatment of the mixed $\mathrm{HAc} / \mathrm{CB}$ solvent with different volume ratios conditions. Average PCE values were based on 8 devices of each type

\begin{tabular}{llllll}
\hline Treatment type & $\begin{array}{l}J_{\mathrm{sc}} \\
\left(\mathrm{mA} \mathrm{cm}^{-2}\right)\end{array}$ & $\begin{array}{l}V_{\text {oc }} \\
(\mathrm{V})\end{array}$ & $\begin{array}{l}\mathrm{FF} \\
(\%)\end{array}$ & $\begin{array}{l}\mathrm{PCE}_{\text {average }} \\
(\%)\end{array}$ & $\begin{array}{l}\text { PCE }_{\text {best }} \\
(\%)\end{array}$ \\
\hline Control & 15.38 & 1.02 & 73 & $11.44 \pm 0.52$ & 12.05 \\
With CB (w/o HAc) & 15.46 & 1.01 & 75 & $11.64 \pm 0.42$ & 12.17 \\
$1: 50$ HAc with CB & 16.13 & 1.01 & 75 & $12.41 \pm 0.31$ & 12.88 \\
$1:$ 25 HAc with CB & 16.47 & 1.03 & 75 & $12.80 \pm 0.30$ & 13.15 \\
$3: 50$ HAc with CB & 15.93 & 1.03 & 75 & $12.24 \pm 0.30$ & 12.61
\end{tabular}

EQE is product of light harvesting efficiency, charge injection/ transfer efficiency, and charge collection efficiency. The light harvesting efficiency is higher in the experimental condition of $\mathrm{H} / \mathrm{CVT}$ films than the control device, indicating that H/CVT will contribute to the higher photo-to-electron conversion efficiency. The improvement of film quality is favourable to the charge transport and the light absorption, than the highest $J_{\mathrm{sc}}$ of the $1 /$ 25 volume ratios H/CVT device was achieved. Each device shows almost same values of $V_{\text {oc }}$, which is plausible as $V_{\text {oc }}$ determined by the difference between the electron quasi-Fermi level of ntype semiconductor (PCBM in our device) and hole quasiFermi level of p-type semiconductor (PEDOT:PSS in our device). ${ }^{38}$

An excitation light of $505 \mathrm{~nm}$ falls on the glass/MAPbI ${ }_{3}$ film without and with various volume ratio $\mathrm{HAc} / \mathrm{CB}$ mixing vapor treatment from the air side, and the photoluminescence (PL)

Table 2 Photovoltaic performance of perovskite solar cells with device architecture of ITO/PEDOT:PSS $/ \mathrm{CH}_{3} \mathrm{NH}_{3} \mathrm{Pbl}_{3} / \mathrm{PCBM} / \mathrm{Al}$ in some reported works

\begin{tabular}{llllll}
$J_{\text {sc }}\left(\mathrm{mA} \mathrm{cm}^{-2}\right)$ & $V_{\text {oc }}(\mathrm{V})$ & $\mathrm{FF}(\%)$ & $\mathrm{PCE}_{\text {average }}(\%)$ & PCE $_{\text {best }}(\%)$ & Ref. \\
\hline 16.62 & 0.92 & 80 & 11.80 & 12.20 & 17 \\
18.02 & 0.85 & 75 & 11.43 & - & 32 \\
19.12 & 0.87 & 73 & 11.62 & 12.13 & 33 \\
18.6 & 0.92 & 72 & - & 12.30 & 34 \\
19.2 & 0.85 & 71 & 11.50 & - & 35 \\
16.12 & 1.05 & 67 & - & 12.04 & 36
\end{tabular}



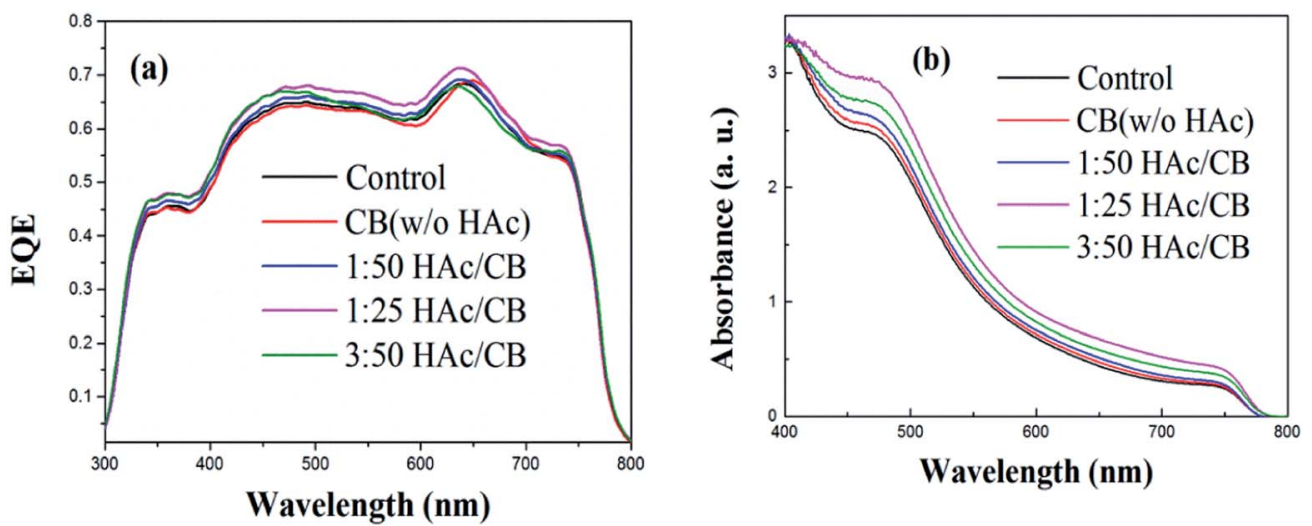

Fig. 4 (a) EQE spectra of devices treated without and with different volume ratios HAc/CB (b) UV-vis absorption spectra of MAPbl 3 film were treated without and with various volume ratios $\mathrm{HAc} / \mathrm{CB}$.

signal was also collected from the air side to compared the film quality. All samples exhibit a PL peak at $766 \mathrm{~nm}$ in Fig. 5(a), which is in agreement with the data reported elsewhere. ${ }^{32,39}$ Generally, the photoluminescence emission is related to the charge carrier recombination of the bandgap and trap states. The phenomenon may imply the perovskite thin film under $\mathrm{H} /$ CVT process has a lower trap density around the band-edge than the control film due to the relative high intensity of PL, which is expected to reduce the recombination loss and improve the photocurrent collection. Meanwhile, we measured the timeresolved PL decay curves of a glass $/ \mathrm{MAPbI}_{3}$ film without and with various volume ratio $\mathrm{HAc} / \mathrm{CB}$ mixing vapor treatment as shown in Fig. 5(b). From the deconvolution of the time-resolved PL decays with a tri-exponential function, the average PL lifetime of $1 / 25$ volume ratios $\mathrm{H} / \mathrm{CVT}$ film( $\sim 118.25 \mathrm{~ns})$ is longer than that of control film ( $93.12 \mathrm{~ns}$ ) as listed in Table 3, which
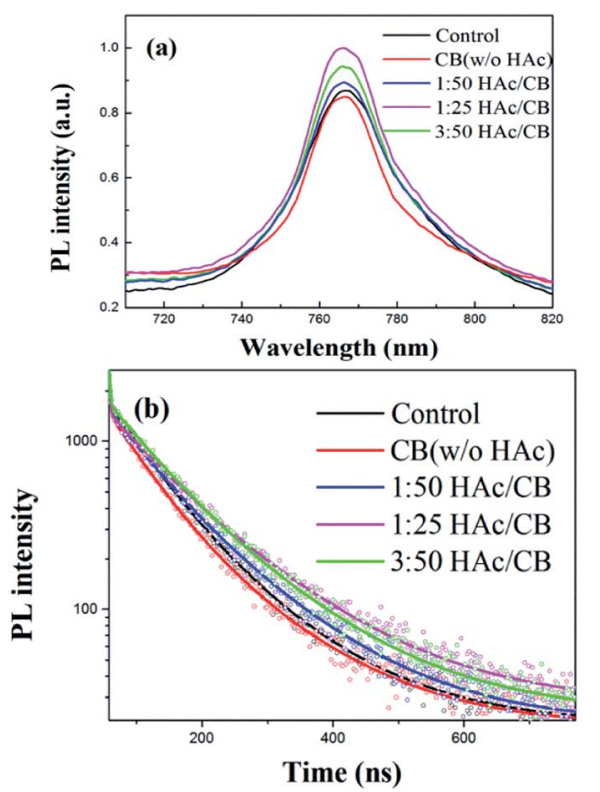

Fig. 5 (a) Steady-state photoluminescence spectra of $\mathrm{MAPb}_{3}$ film coated on glass substrate; (b) time-resolved photoluminescent decay curves of glass/MAPb| ${ }_{3}$ film were treated without and with various volume ratios $\mathrm{HAc} / \mathrm{CB}$. is comparable to the value found in $\mathrm{MAPbI}_{3}$ film in previous reports. ${ }^{39}$ The faster PL quenching in the control film than in the H/CVT film confirms that the recombination loss of the charge carriers in the control film is more than that of $\mathrm{H} / \mathrm{CVT}$ film. It indicates the improved H/CVT film suppresses the nonradiative recombination channels.

The variation of the carrier recombination in PSCs also correlates with the crystallization property of the perovskite thin films. Hence, the scanning electron microscope (SEM) images and X-ray diffraction (XRD) spectroscopy of $\mathrm{MAPbI}_{3}$ thin films without and with $\mathrm{H} / \mathrm{CVT}$ process were measured. The crystallization of the $\mathrm{MAPbI}_{3}$ film is a crucial parameter, which is correlated to the light-absorption ability, charge transport and recombination properties of PSCs. The large grain size and good crystallinity will lead to a high performance of the resulting devices. ${ }^{40}$ Fig. $6(\mathrm{a})$ shows the X-ray diffraction (XRD) spectroscopy of the $\mathrm{MAPbI}_{3}$ film treated by $1 / 25$ volume ratio $\mathrm{HAc} / \mathrm{CB}$ mixing solvent and without, respectively. With the similar film thickness and under the same measurement condition, the diffraction peak intensity (110) of the $\mathrm{MAPbI}_{3}$ film processed with HAc vapor treatment is higher than that of the $\mathrm{MAPbI}_{3}$ film without HAc treatment. In general, XRD peak intensity is related to the crystal orientation and surface porosity. The XRD spectra present intense diffraction peaks at $14.50^{\circ}, 28.84^{\circ}$, and $32.28^{\circ}$ in two samples, corresponding to (110), (220), and (310) crystal planes of $\mathrm{MAPbI}_{3}{ }^{41}$ respectively. SEM images shown in Fig. 6(b)-(f) reveal an interesting phenomena that the grain size

Table 3 Time resolved photoluminescence decay characterization

\begin{tabular}{|c|c|c|c|c|c|c|c|}
\hline $\begin{array}{l}\text { Treatment } \\
\text { type }\end{array}$ & $\begin{array}{l}\tau_{1} \\
(\mathrm{~ns})\end{array}$ & $\begin{array}{l}\text { Fraction } \\
1\end{array}$ & $\begin{array}{l}\tau_{2} \\
\text { (ns) }\end{array}$ & $\begin{array}{l}\text { Fraction } \\
2\end{array}$ & $\begin{array}{l}\tau_{3} \\
\text { (ns) }\end{array}$ & $\begin{array}{l}\text { Fraction } \\
3\end{array}$ & $\begin{array}{l}\text { Average } \\
\text { (ns) }\end{array}$ \\
\hline Control & 1.00 & $3.34 \%$ & 65.92 & $55.64 \%$ & 137.52 & $41.02 \%$ & 93.12 \\
\hline $\begin{array}{l}\text { With CB } \\
\text { (w/oHAc) }\end{array}$ & 1.05 & $4.45 \%$ & 60.88 & $50.79 \%$ & 139.19 & $44.76 \%$ & 93.26 \\
\hline $\begin{array}{l}1: 50 \mathrm{HAc} \\
\text { with CB }\end{array}$ & 1.06 & $3.60 \%$ & 67.39 & $40.82 \%$ & 137.22 & $55.58 \%$ & 103.81 \\
\hline $\begin{array}{l}1: 25 \mathrm{HAc} \\
\text { with } \mathrm{CB}\end{array}$ & 1.06 & $3.12 \%$ & 67.81 & $26.91 \%$ & 142.97 & $69.93 \%$ & 118.25 \\
\hline $\begin{array}{l}3: 50 \mathrm{HAc} \\
\text { with CB }\end{array}$ & 0.97 & $2.87 \%$ & 71.50 & $40.92 \%$ & 143.38 & $56.21 \%$ & 109.88 \\
\hline
\end{tabular}



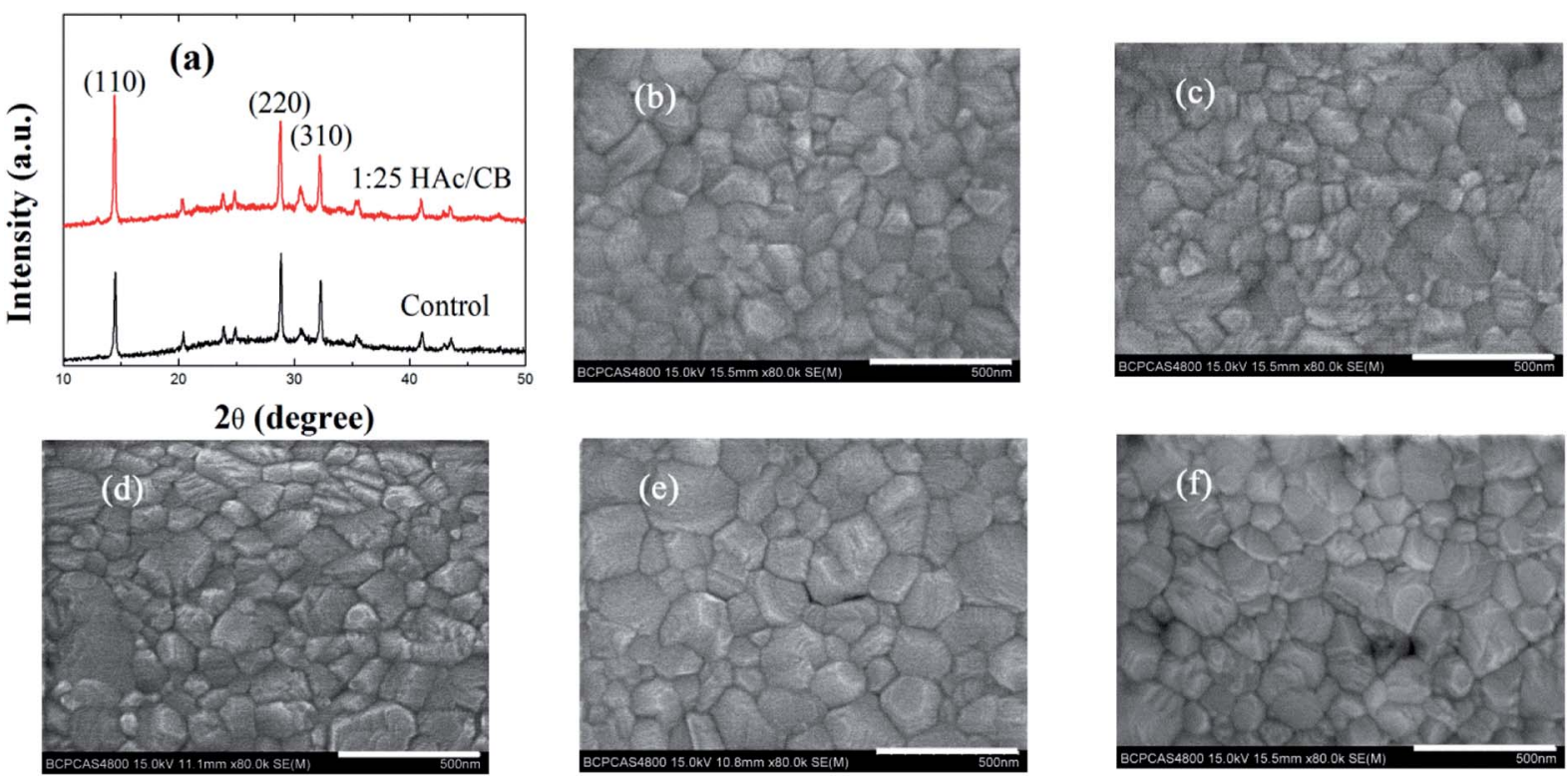

Fig. 6 (a) XRD patterns of $\mathrm{MAPb}_{3}$ films were treated without and with 1/25 volume ratios $\mathrm{HAc} / \mathrm{CB}$, respectively; (c) SEM image of the MAPbI film prepared with CB vapor treatment; (b), (d), (e) and (f) SEM images of MAPbl 3 films prepared without and with 1/50, 1/25, 3/50 volume ratios HAc/ $C B$, respectively, scale bar is $500 \mathrm{~nm}$.

of the perovskite film with $\mathrm{HAc} / \mathrm{CB}$ mixed solvent treatment is larger than that only annealing processes. Extremely the $\mathrm{MAPbI}_{3}$ film of $1 / 25$ volume ratios $\mathrm{HAc} / \mathrm{CB}$ mixing solution shows a larger grain, which is comparable to other treated films. The average $\mathrm{MAPbI}_{3}$ grain size of the film treated with $1 / 25 \mathrm{H} /$ CVT and only TA is circa $160 \mathrm{~nm}$ and $130 \mathrm{~nm}$, respectively. Using nano measurer software, we assess the maximum grain size of $\mathrm{MAPbI}_{3}$ film treated with $1 / 25 \mathrm{H} / \mathrm{CVT}$ and only TA is $360 \mathrm{~nm}$ and $310 \mathrm{~nm}$, respectively. The enlargement of the perovskite grain size reveals fewer grain boundaries which correlate to a lower trap density. ${ }^{2,35,39,42,43}$ As the recombination in PSCs is evidenced to be governed by the trap states ${ }^{44}$ the larger grain size of the perovskite film with HAc/CB mixed solvent vapor treatment indicates less recombination. Hence, we can conclude that the large grain size of the perovskite thin films with $\mathrm{HAc} / \mathrm{CB}$ mixed solvent treatment contribute to decrease the charge carrier recombination. This result is in accordance with the XRD patterns, and reveales that with HAc/ CB mixed solvent treatment perovskite thin films are favor to the growth of large grain $\mathrm{MAPbI}_{3}$ films.

\section{Conclusions}

In summary, we have demonstrated a route to treat $\mathrm{MAPbI}_{3}$ perovskite layers by mixed solvents with $\mathrm{HAc}$ and $\mathrm{CB}$, which improves the photoelectric characteristic of the corresponding PSCs, and significantly boosts the devices efficiency ( $\approx 15 \%)$. The PSCs treated by $1 / 25$ volume ratios H/CVT show a greater photocurrent and less charge carries non-radioactive recombination. We attribute the enhancements to the improved light absorption and the larger grain size that helps to reduce carries losses. This work provides the significant development potential of solvent vapor treatment process after the thermal annealing of perovskite thin films, which emphasizes an effective strategy to facilitate the efficient device performance of the planar heterojunction PSCs toward practical applications in the future.

\section{Conflicts of interest}

There are no conflicts to declare.

\section{Acknowledgements}

The authors express the thanks to the National Natural Science Foundation of China under Grant No. 61575019 and the Fundamental Research Funds for the Central Universities with the Grant No. 2017RC015.

\section{References}

1 C. Wehrenfennig, M. Liu, H. J. Snaith, M. B. Johnston and L. M. Herz, Energy Environ. Sci., 2014, 7, 2269-2275.

2 Z. Xiao, Q. Dong, C. Bi, Y. Shao, Y. Yuan and J. Huang, Adv. Mater., 2014, 26, 6503-6509.

3 D. Shi, V. Adinolfi, R. Comin, M. Yuan, E. Alarousu, A. Buin, Y. Chen, S. Hoogland, A. Rothenberger and K. Katsiev, Science, 2015, 347, 519-522.

4 Q. Lin, A. Armin, R. C. R. Nagiri, P. L. Burn and P. Meredith, Nat. Photonics, 2015, 9, 106.

5 Q. Dong, Y. Fang, Y. Shao, P. Mulligan, J. Qiu, L. Cao and J. Huang, Science, 2015, 347, 967-970.

6 S. D. Stranks, G. E. Eperon, G. Grancini, C. Menelaou, M. J. Alcocer, T. Leijtens, L. M. Herz, A. Petrozza and H. J. Snaith, Science, 2013, 342, 341-344. 
7 D. Yang, R. Yang, X. Ren, X. Zhu, Z. Yang, C. Li and S. F. Liu, Adv. Mater., 2016, 28, 5206-5213.

8 W. S. Yang, B.-W. Park, E. H. Jung, N. J. Jeon, Y. C. Kim, D. U. Lee, S. S. Shin, J. Seo, E. K. Kim and J. H. Noh, Science, 2017, 356, 1376-1379.

9 A. Kojima, K. Teshima, Y. Shirai and T. Miyasaka, J. Am. Chem. Soc., 2009, 131, 6050-6051.

10 S. Kazim, M. K. Nazeeruddin, M. Grätzel and S. Ahmad, Angew. Chem., Int. Ed., 2014, 53, 2812-2824.

11 M. M. Lee, J. Teuscher, T. Miyasaka, T. N. Murakami and H. J. Snaith, Science, 2012, 1228604.

12 H.-S. Kim, C.-R. Lee, J.-H. Im, K.-B. Lee, T. Moehl, A. Marchioro, S.-J. Moon, R. Humphry-Baker, J.-H. Yum and J. E. Moser, Sci. Rep., 2012, 2, 591.

13 J. M. Ball, M. M. Lee, A. Hey and H. J. Snaith, Energy Environ. Sci., 2013, 6, 1739-1743.

14 M. Liu, M. B. Johnston and H. J. Snaith, Nature, 2013, 501, 395.

15 Q. Chen, H. Zhou, Z. Hong, S. Luo, H.-S. Duan, H.-H. Wang, Y. Liu, G. Li and Y. Yang, J. Am. Chem. Soc., 2013, 136, 622625.

16 L. Etgar, P. Gao, Z. Xue, Q. Peng, A. K. Chandiran, B. Liu, M. K. Nazeeruddin and M. Grätzel, J. Am. Chem. Soc., 2012, 134, 17396-17399.

17 J. Seo, S. Park, Y. C. Kim, N. J. Jeon, J. H. Noh, S. C. Yoon and S. I. Seok, Energy Environ. Sci., 2014, 7, 2642-2646.

18 P. W. Liang, C. Y. Liao, C. C. Chueh, F. Zuo, S. T. Williams, X. K. Xin, J. Lin and A. K. Y. Jen, Adv. Mater., 2014, 26, 3748-3754.

19 M. Yang, T. Zhang, P. Schulz, Z. Li, G. Li, D. H. Kim, N. Guo, J. J. Berry, K. Zhu and Y. Zhao, Nat. Commun., 2016, 7, 12305.

20 F. Xu, T. Zhang, G. Li and Y. Zhao, ChemSusChem, 2017, 10, 2365-2369.

21 N. J. Jeon, J. H. Noh, Y. C. Kim, W. S. Yang, S. Ryu and S. I. Seok, Nat. Mater., 2014, 13, 897.

22 W. S. Yang, J. H. Noh, N. J. Jeon, Y. C. Kim, S. Ryu, J. Seo and S. I. Seok, Science, 2015, 348, 1234-1237.

23 Q. Wang, Y. Shao, Q. Dong, Z. Xiao, Y. Yuan and J. Huang, Energy Environ. Sci., 2014, 7, 2359-2365.

24 N. Lin, J. Qiao, H. Dong, F. Ma and L. Wang, J. Mater. Chem. A, 2015, 3, 22839-22845.

25 Y. Yuan and J. Huang, Acc. Chem. Res., 2016, 49, 286-293.

26 B. Conings, J. Drijkoningen, N. Gauquelin, A. Babayigit, J. D'Haen, L. D'Olieslaeger, A. Ethirajan, J. Verbeeck,
J. Manca and E. Mosconi, Adv. Energy Mater., 2015, 5, 1500477.

27 N. Ahn, D.-Y. Son, I.-H. Jang, S. M. Kang, M. Choi and N.-G. Park, J. Am. Chem. Soc., 2015, 137, 8696-8699.

28 W. Li, J. Fan, J. Li, G. Niu, Y. Mai and L. Wang, ACS Appl. Mater. Interfaces, 2016, 8, 30107-30115.

29 S. Pang, H. Hu, J. Zhang, S. Lv, Y. Yu, F. Wei, T. Qin, H. Xu, Z. Liu and G. Cui, Chem. Mater., 2014, 26, 1485-1491.

30 Q. Chen, H. Zhou, T.-B. Song, S. Luo, Z. Hong, H.-S. Duan, L. Dou, Y. Liu and Y. Yang, Nano Lett., 2014, 14, 4158-4163.

31 K. G. Lim, H. B. Kim, J. Jeong, H. Kim, J. Y. Kim and T. W. Lee, Adv. Mater., 2014, 26, 6461-6466.

32 D. Huang, T. Goh, J. Kong, Y. Zheng, S. Zhao, Z. Xu and A. D. Taylor, Nanoscale, 2017, 9, 4236-4243.

33 X. Huang, K. Wang, C. Yi, T. Meng and X. Gong, Adv. Energy Mater., 2016, 6, 1501773.

34 X. Gong, M. Li, X. B. Shi, H. Ma, Z. K. Wang and L. S. Liao, Adv. Funct. Mater., 2015, 25, 6671-6678.

35 C. Bi, Q. Wang, Y. Shao, Y. Yuan, Z. Xiao and J. Huang, Nat. Commun., 2015, 6, 7747.

36 O. Malinkiewicz, A. Yella, Y. H. Lee, G. M. Espallargas, M. Graetzel, M. K. Nazeeruddin and H. J. Bolink, Nat. Photonics, 2014, 8, 128.

37 Z. Zhu, Y. Bai, T. Zhang, Z. Liu, X. Long, Z. Wei, Z. Wang, L. Zhang, J. Wang and F. Yan, Angew. Chem., 2014, 126, 12779-12783.

38 B. Cai, Y. Xing, Z. Yang, W.-H. Zhang and J. Qiu, Energy Environ. Sci., 2013, 6, 1480-1485.

39 Y. Li, Z. Xu, S. Zhao, B. Qiao, D. Huang, L. Zhao, J. Zhao, P. Wang, Y. Zhu and X. Li, Small, 2016, 12, 4902-4908.

40 W. Nie, H. Tsai, R. Asadpour, J.-C. Blancon, A. J. Neukirch, G. Gupta, J. J. Crochet, M. Chhowalla, S. Tretiak and M. A. Alam, Science, 2015, 347, 522-525.

41 Q. Xue, Z. Hu, J. Liu, J. Lin, C. Sun, Z. Chen, C. Duan, J. Wang, C. Liao and W. M. Lau, J. Mater. Chem. A, 2014, 2, 19598-19603.

42 Y. Shao, Y. Fang, T. Li, Q. Wang, Q. Dong, Y. Deng, Y. Yuan, H. Wei, M. Wang and A. Gruverman, Energy Environ. Sci., 2016, 9, 1752-1759.

43 J.-H. Im, I.-H. Jang, N. Pellet, M. Grätzel and N.-G. Park, Nat. Nanotechnol., 2014, 9, 927-932.

44 G. J. A. Wetzelaer, M. Scheepers, A. M. Sempere, C. Momblona, J. Ávila and H. J. Bolink, Adv. Mater., 2015, 27, 1837-1841. 